\title{
Aproximación a la percepción social sobre el sistema tributario colombiano a partir de una revisión teórica
}

\section{Approach to the social perception of the Colombian tax system based on a theoretical review}

DOI: https://doi.org/10.17981/econcuc.41.2.2020.Econ.3

Artículo de revisión.

Fecha de recepción: 19/03/2020

Fecha de devolución: 30/05/2020

Fecha de aceptación: 10/06/2020

Fecha de publicación: 25/06/2020

\section{José Wilmar Pino Montoya \\ Universidad Católica Luis Amigó. Medellín (Colombia) jose.pinomo@amigo.edu.co}

\section{Juliana Carolina Farfán Rodríguez ii Corporación Universitaria Remington. Medellín (Colombia) juliana.farfan@uniremington.edu.co}

\section{Ruby Stella Cabrera Jaramillo Universidad Católica Luis Amigó. Medellín (Colombia) ruby.cabreraja@amigo.edu.co}

Para citar este artículo:

Pino, J., Farfán, J. \& Cabrera, S. (2020). Aproximación a la percepción social sobre el sistema tributario colombiano a partir de una revisión teórica. Económicas CUC, 41(2), 197-210. DOI: https://doi.org/10.17981/ econcuc.41.2.2020.Econ.3

\begin{abstract}
Resumen
La economía pública se justifica mediante los objetivos fiscales, para lo cual se sustenta en las estructuras tributarias, estructuras mismas que pueden tener problemáticas en el recaudo progresivo de los tributos, sin menoscabo de la actividad económica o de los ciudadanos. En este sentido, el presente artículo de revisión documental se deriva del proyecto de investigación: percepción social del pequeño contribuyente sobre el impuesto de renta del sistema tributario colombiano, en el que se analiza cómo la apreciación del ciudadano puede influir en el cumplimiento de las responsabilidades fiscales. La hipótesis que fundamenta este estudio es que la relación de las categorías: sistema social de derecho, fines del Estado, ingresos tributarios y pequeños contribuyentes, convergen en la constitucionalidad del sistema de renta colombiano, que permite una percepción social positiva del sistema y es por ello que en este documento se desarrolla un análisis conceptual, para aportar, desde la teoría un mejor entendimiento del sistema tributario, que sirva de fundamento para posteriores estudios empíricos sobre la política fiscal de Colombia y a partir de allí se fortalezca los mecanismos de recaudo del impuesto. Se concluye que de acuerdo a los fines de equidad social y el bien común que deriva del Estado, se hace necesario fortalecer un sistema tributario que garantice el cumplir su función y que es un deber ciudadano coadyuvar al Estado a través de la extinción de la obligación tributaria que le competa.

Palabras clave: Percepción social; Sistema tributario; Pequeño Contribuyente; responsabilidad fiscal
\end{abstract}

\begin{abstract}
The public economy is justified by fiscal objectives, for which it is based on tax structures, structures that can have problems in the progressive collection of taxes, without detriment to economic activity or citizens. In this sense, this documentary review article is derived from the research project: social perception of the small taxpayer about the income tax of the Colombian tax system, which analyzes how the appreciation of the citizen can influence the fulfillment of fiscal responsibilities. The hypothesis underlying this study is that the relationship of the categories: social system of law, ends of the State, tax revenues and small taxpayers, converge in the constitutionality of the Colombian income system, which allows a positive social perception of the system and is by This is why in this document a conceptual analysis is developed, to provide, from the theory, a better understanding of the tax system, which serves as the basis for subsequent empirical studies on the fiscal policy of Colombia and from there strengthen the tax collection mechanisms. It is concluded that according to the purposes of social equity and the common good that derives from the State, it is necessary to strengthen a tax system that guarantees the fulfillment of its function and that it is a citizen's duty to assist the State through the extinction of the obligation tax responsibility. Keywords: Social perception; Tax system; Small Taxpayer; fiscal responsibility
\end{abstract}




\section{INTRODUCCIÓN}

Las estructuras tributarias pueden contener problemáticas que entorpezcan el alcance de los principales objetivos fiscales, desde el deber ser de la economía pública, es decir lograr un recaudo efectivo sin perjudicar la actividad económica ni el bienestar social de los ciudadanos; ahora bien, el cumplimiento de obligaciones fiscales por parte de los contribuyentes está influenciado por la percepción de los mismos sobre el sistema tributario, en este sentido se propone en este documento su análisis desde cuatro categorías: Estado Social de Derecho y fines del Estado, Equidad y eficiencia en el sistema tributario, ingresos públicos tributarios, percepción social del Sistema Tributario por los pequeños contribuyentes, cuyo desarrollo teórico y conceptual favorece su comprensión, pues la sensibilidad de lo perceptivo es una variable determinante en el comportamiento del sujeto pasivo frente a su obligación de "dar" en el marco de lineamientos constitucionales.

Sobre la importancia que un Estado tenga un sistema tributario, la describe muy bien el premio Nobel de Economía en 1996, James Mirrless, quien en uno de sus informes conceptualiza que "el sistema tributario es el pilar fundamental del Estado moderno, es determinante del modelo económico y social del siglo XXI" (Mirrless et al., 2013, p. 53). Reflexión que complementa Montero (1995), al describir que "todo sistema tributario está estrechamente ligado con principios políticos que persigue el país" (p. 64). De allí que la política fiscal y económica debe procurar desde sus raíces constitucionales un diseño del marco fiscal favorable para las condiciones socioeconómicas del territorio, ya que el impacto económico de los tributos sobre la sociedad puede incidir en la percepción positiva o negativa de los ciudadanos frente a sus legisladores y gobernantes, influyendo en el fortalecimiento o debilitamiento del Estado y su sistema democrático. Bravo (2014) hace referencia a las disertaciones de Schmolders sobre psicología y económica, considerando que: "el concepto de sistema tributario implica cierta coordinación de los diferentes impuestos entre sí con el sistema económico dominante y con fines fiscales y extrafiscales de la imposición" (p. 12). No obstantes, otras posturas sociopolíticas de corte capitalista perciben los impuestos como el mecanismo que permite a la sociedad retribuir al Estado el costo de ofrecer su macroestructura de gobernanza para garantizar desarrollo y crecimiento empresarial, pilares generadores de riqueza y avance de la modernización social (Alvaredo y Londoño, 2014).

La revisión acá expuesta pretende aproximar, desde lo teórico los criterios que definen la "percepción social" sobre el sistema tributario colombiano, por ello la primera categoría explicativa del sistema tributario colombiano, propuesta en este documento es el concepto de Estado Social de Derecho y fines del Estado, donde la potestad tributaria se subordina a la supremacía constitucional y debe cumplir una función extrafiscal redistributiva. La segunda categoría, equidad y eficiencia en el sistema tributario colombiano, intenta asignar un equilibrio entre la necesidad de ingresos y el bienestar social, así en las decisiones fiscales y tributarias, el interés y beneficio selectivo se establecen por encima de los intereses colectivos, razón de ser en una sociedad de derecho democrático; los ingresos públicos como tercera categoría que se desarrolla son la principal fuente de recursos para el sostenimiento del Estado. Sin embargo el ánimo 
recaudatorio de los tributos podría violentar un poco los fundamentos constitucionales e impactar negativamente en la sociedad cuando su base normativa busca aumentar la carga fiscal sin considerar sus efectos negativos, Chumaceiro y Hernández (2012) y López y Chaparro (2014) consideran que esto tiene lugar cuando contiene características estructurales que le impiden el cumplimiento del principio tributario de la equidad, y por tanto, los cambios a nivel tributario son de tipo coyuntural; finalmente se esboza la percepción social del Sistema Tributario por los pequeños contribuyentes como última categoría busca resaltar la importancia de una percepción favorable por parte de los ciudadanos para el sistema tributario.

\section{Metodología}

La revisión del tema es de carácter documental y descriptivo, para su derrotero metodológico se tomó el enfoque histórico hermenéutico, la revisión tubo una etapa exploratoria que consistió en el rastreo documental de fuentes primarias y secundarias encontradas en bases de datos electrónicas como Dialnet, Redalyc, SciELO, World Wide Science, ScienceResearchc, Latindex y Scopus. Igualmente, se tomó de referencia materia bibliográfico físico de revistas especializadas, memorias de congresos y publicaciones científicas y académicas recomendadas en centros especializados como el Instituto Colombiano de Derecho Tributario, LEGIS, entre otros. Los documentos seleccionados fueron organizados en una matriz de análisis simple y tomados como fuente de referencia a la sustentación en torno a la "percepción social" sobre el sistema tributario colombiano; implementada esta metodología se busca que el lector pueda sintetizar el debate acerca de la percepción del sistema tributario teniendo en cuenta las variables desarrolladas, su contenido busca ser un proceso de apropiación social y académica del saber (Sánchez, 2016).

\section{ANÁLISIS}

\section{Estado social de derecho y fines del Estado}

El Estado social de derecho es definido en el artículo 1 de la Constitución Política de Colombia, como un precepto que obliga al Estado a ser respetuoso de la ley, en defensa de la libertad y propiedad privada de los ciudadanos, esto implica mayor exigencia en el ejercicio democrático y de seguridad jurídica (Const., 1991, art. 1); al hablar de protección de libertades se debe hacer referencia al respeto por los derechos e intereses de los ciudadanos. El Estado social es definido por Reales (2016), Hernández, Chumaceiro y Ravina y Borda (2007) como aquel que logra incorporar la constitución y por consecuente el orden jurídico y derechos sociales, civiles y políticos de los ciudadanos, los cuales demandan prestaciones sociales al "Estado de bienestar". Por su parte, Jinú tomando de referencia a Lorenz Vonz Stein, afirma que la finalidad del Estado debe ser el dar solución a los problemas sociales, lo cual implica la protección y asistencia de la población que no sustenta del recurso económico (Jinú, 2013), es decir, se debe promover la equidad social real. 
Ese estado de bienestar que promueve todo Estado social de derecho debe darle prioridad a la satisfacción de necesidades básicas como empleo, beneficios sociales, salud y pensión, educación, seguridad, acceso a servicios básicos, así como la reducción de la pobreza extrema (Casas, 2017); el concepto de Estado social fue propuesto por Heller (citado por Borda, 2007), quien consideraba que el derecho, por sí solo, no daría la prioridad necesaria a la igualdad como objeto social en el actuar del Estado y, por tanto, el derecho se podía orientar hacia la protección de las elites sociales, desvirtuando su función.

\section{Equidad y eficiencia en el sistema tributario colombiano}

El principio de legalidad obliga a estudiar la norma y que su implementación se fundamenta en el bien común que, de vida al tributo, bajo los principios de equidad, eficiencia y progresividad, sin embargo, para promover la equidad el Estado de Bienestar, necesita tener solvencia económica, la cual se logra con la recaudación eficiente del tributo. Para el caso colombiano, hay diferentes percepciones que dificultan el cumplimientos de dichos recaudos, así Villabona y Quimbay (2017) sustentan en su artículo la presencia de inequidad horizontal por cuenta de los beneficios tributarios, esto al evidenciar que la tasa efectiva de impuesto de renta liquidadas por las empresas no representaban una diferencia significa entre sectores económicos. Misma conclusión a la que llegaron los autores Paz, Harris y Franco (2016) y Paredes-Chacín (2017) en una investigación orientada hacia las responsabilidades; además Villabona y Quimbay (2017) resaltaron que las tasas más bajas se presentaban en el sector financiero y la minería, básicamente por la aplicación de beneficios tributarios. Las principales consecuencias de esto es el aumento de la complejidad del sistema tributario, la disminución en el recaudo y el aumento de la evasión (Jaimes y Fuente, 2017; De la Torre, 2018), además es importante resaltar que los beneficios diferenciales entre sectores económicos representan altos costos para aquellos menos favorecidos por las reformas, los cuales generalmente soportan cargas más altas que perjudican la rentabilidad y por tanto la inversión, las consecuencias negativas en el mediano y largo plazo se pueden ver reflejas en disminución en la generación de empleo.

Las reformas tributarias que se implementen pueden modificar el cumplimiento de los principios ya mencionados, a favor de intereses coyunturales de la economía o diferentes grupos de intereses que tengan potestad de intervenir, al respecto, Corredor y González (2016) consideran que las reformas estructurales implementadas en Colombia entre el periodo 1990-2018, han sido objeto de múltiples críticas, por carecer de una base estructural en sus modificaciones, consideradas como no integrales; Toscano (2013) les atribuye la característica de poco progresistas por la ausencia de progresividad y proporcionalidad en el aumento de sus tarifas.

Con respecto a la efectividad y eficiencia para disminuir el déficit fiscal y cumplir las necesidades de gasto público del gobierno, Herrera, Larrea, Gallo y Uribe (2012) estudiaron las reformas que tuvieron lugar en el período 1990 - 2009, para describir su carácter mediático, coyuntural y no estructural, teniendo en cuenta los objetivos intermedios y básicos de cada una de ellas; además consideran que no guardaban re- 
lación con el ciclo económico del país, ni criterios de eficiencia económica que incluyan un estudio acertado sobre los efectos de las medidas impuestas en relación a los costos económicos, sociales y fiscales; por ejemplo, consideran la evasión y elusión como un costo fiscal producto de inequidades y debilidades del sistema; frente a los beneficios tributarios afirman que estos propician la captura de rentas por sectores que poco aportan a la económica en inversión y generación de empleo, lo cual ahonda más la inequidad del sistema.

Por su parte Masbernat (2014) afirma que los sistemas tributarios deben garantizar la certeza como la posibilidad de que el contribuyente identifique tiempo, forma y características del impuesto a cargo, pues la carga tributaria debe representar el menor esfuerzo posible para no alterar negativamente las decisiones de consumo e inversión, lo que repercute en el dinamismo de la economía en su conjunto, tal como lo describe el economista clásico Adam Smith citado por Masbernat (2014). Ramírez, Sánchez y Silva (2018) por su parte, estudiaron la complejidad del sistema tributario colombiano, enfocados en determinar los efectos negativos sobre la informalidad, para finalmente proponer alternativas fiscales, afirman que, pese a que la constitución política establece los principios tributarios de equidad, eficiencia y progresividad, las constantes reformas tributarias aumentan la complejidad del sistema, lo cual crea un ambiente propicio para la elusión y la evasión.

\section{Ingresos Públicos}

La herramienta principal de un Estado democrático que además evidencia los objetivos sociales de los gobernantes, es la política fiscal, la cual, es según Cárdenas y Vargas (citado en Vega, Brito, Apolo y Sotomayor, 2020), como "una herramienta de estabilización macroeconómica, de redistribución del ingreso y de riqueza, que es utilizada por el Estado, siendo sus componentes principales: gasto público, impuestos y deuda pública, se materializa por medio de presupuesto del Estado” (p. 2). En este orden de ideas, el concepto de recaudo de ingresos implica desarrollar uno de los pilares de la hacienda pública y de la política fiscal, denominados "ingresos públicos", que permiten ejecutar los fines esenciales del Estado a partir de la percepción de los involucrados en una democracia garante del orden constitucional (Kohn, 2014).

Entonces, el recaudo de los tributos se enmarca en la potestad y el uso de la fuerza legítima del Estado para otorgar obligaciones tributarias a los miembros de una nación soberana, es decir, obliga a desprenderse de una porción de su capital económico en aras de financiar los fines esenciales para los cuales ha sido creado. Linde (2018) define dicha potestad como un actuar de poder que habilita a un titular imponer conductas a terceros mediante la constitución, modificación o extinción de relaciones jurídicas, o modificación del Estado.

Para Adam Smith (según Retchkiman, 1976), el ingreso de los ciudadanos debe ser la medida relevante para el pago de gravámenes es decir, todos los súbditos de cualquier Estado, tienen la obligación de aportar al sostenimiento del mismo, en una cantidad proporcional a los ingresos que adquieren gracias a la explotación económica que realiza dentro del territorio, donde obtienen dichos ingresos. De Soto (2004) considera que 
la afirmación de Adam Smith se puede interpretar como una medida para establecer el monto de la carga fiscal, de tal forma que sea proporcional a la renta obtenida por el contribuyente.

El orden jurídico le reconoce al Estado el poder para imponer cargas tributarias, con amplias facultades legislativas, reglamentarias y de control institucional. Masbernat (2002) afirma que por medio del poder legislativo el Estado tiene el control exclusivo sobre los tributos, para establecer sus elementos esenciales y dirimir las controversias entre la administración y los contribuyentes, o bien entre este último y el poder legislativo en relación a la legalidad o la constitucionalidad de los poderes ejercidos por la administración según sea el caso.

El Estado tiene la potestad de exigir el pago de impuestos, tasas, multas, a su vez los ciudadanos tienen el deber de dar parte de sus ingresos como fuente de entrada al presupuesto público; para ejercer el derecho impositivo y coactivo en un Estado Social de Derecho garante de los derechos ciudadanos, es la ley quien crea el tributo dando cumplimiento a lo estipulado en el artículo 150 (Const., 1991, art. 150). El recaudo de ingresos tributarios explícitamente no implica una contrapartida, no existe una relación directa pago - beneficio, no tiene definido un precio, es en sí mismo una obligación ciudadana enmarcada en virtud del artículo 95, según la cual todo ciudadano colombiano debe contribuir al financiamiento del gasto público del Estado, dentro de los conceptos de justicia y equidad (Const., 1991, art. 95); es así como se origina la obligación tributaria de la cual se desprenden obligaciones formales y sustanciales, este conocimiento debe permitir al contribuye ejercer su deber constitucional desde el ejercicio de su ciudadanía, como un acto moral y consciente.

Los tributos constituyen simultáneamente un ingreso fiscal para el sostenimiento del Estado y una herramienta de política fiscal para mejorar el bienestar económico y social (Restrepo, 2012), lo cual es más notorio cuando el ingreso tributario tiene definida su destinación. Así, la justicia tributaria tiene lugar al existir una contrapartida entre el Estado y la sociedad. López y Chaparro (2014) analizan el recaudo de ingresos tributarios en Colombia desde la ética y la equidad, donde exponen que la principal función del Estado, a partir del recaudo es la redistribución del ingreso, en especial entre quienes tienen condiciones económicas más precarias, para ello debe tenerse presente el efecto de los impuestos directos e indirectos sobre la economía.

Masbernat (2014) estudia la justicia del tributo desde la perspectiva inglesa, según esta el recaudo se debe orientar desde la política fiscal a corregir las deficiencias de justicia social; para lograr su objetivo, propone que los elementos básicos que determinan la justicia tributaria estén inmersos en la estructura fiscal por medio de la implementación de normas o decisiones jurídicas que exija la aplicación de parámetros de justicia en las modificación o implementaciones de impuestos o designación del gasto público. Chumaceiro y Hernández (2012) y Rodríguez (2015) por su parte, describen los principios tributarios como aquellos límites que tiene el Estado en la creación de tributos evitando vulnerar los derechos fundamentales de sus ciudadanos.

El profesor Rozas (2012) cita "el corazón constitucional del derecho tributario es, sin duda alguna, el llamado principio de capacidad económica o contributiva” (p. 13). Es por tanto que un justo tributo consulta la capacidad contributiva interpretada como la 
diferencia entre el ingreso y los gastos de que el contribuyente hace uso para satisfacer su subsistencia y la de los suyos en condiciones de calidad y dignidad.

Los elementos del tributo deben considerar la capacidad contributiva, al respecto Roncallo (2019) quien comparte opinión al respecto con Estrada y Mármol (2019) consideran que el haber otorgado una connotación recaudatoria al sistema tributario colombiano, llevó al desconocimiento de la capacidad económica de los contribuyentes e impuso cargas desmedidas a los ciudadanos, que, en algunos casos, al sentir la opresión de Estado recurren a los mecanismos de evasión y elusión. En la jurisprudencia colombiana, la Sentencia C-173/2010 la Corte Constitucional de Colombia conceptualiza la capacidad contributiva como la posibilidad económica de asumir una carga fiscal, de tal forma que dependerá de la obtención de ingresos del ciudadano, es decir, la justicia tributaria deberá exonerar de la obligación de contribuir a quienes obtienen un ingreso básico para subsistir. Para Montero (1995) desconocer la capacidad contributiva del individuo deslegitimiza la legalidad del tributo en la medida en que no existe el flujo de efectivo para soportarlo; la legalidad del tributo se da en la medida en que se pueda demostrar la existencia real del hecho generador que permite al sujeto obtener renta y por tanto adquirir capacidad contributiva.

La afectación económica coercitiva de utilidades por parte de los contribuyente puede percibir la obligación tributaria como una sacrificio obligado al contribuyente, este sacrificio establece diferentes niveles que dependen de la capacidad económica de los contribuyentes, es decir que podrá ser absoluto, proporcional o marginal tal como se sintetiza en la Figura 1.

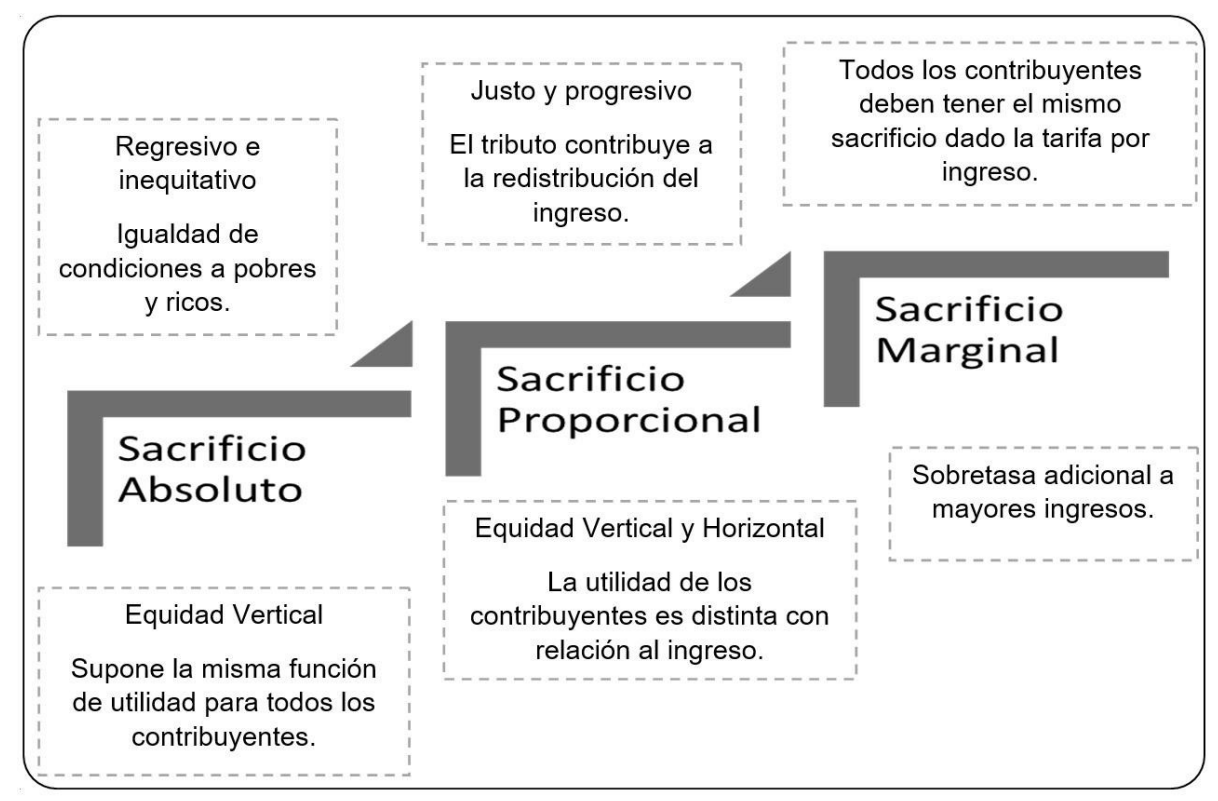

Figura 1. Sacrificios tributarios. Fuente: Elaboración propia.

La equidad vertical explicada por John Stuar Mill, según Musgrave y Peggy (1992), se sostiene sobre la base del sacrificio igual y el trato igualitario para todos los sujetos (lo cual implica para Espitia et al., 2017) una pérdida del bienestar, y se contradice con el sacrificio proporcional en donde la igualdad del tributo debe ser proporcional a la 
capacidad del pago. Para Piza y Sánchez (2017) en el sistema tributario colombiano hay dos tipos de tributos, aquellos con tasas y contribuciones enmarcado en la expresión latina "quid pro quo" que representan las cargas fiscales repartidas en la medida del beneficio que el sujeto obligado perciba del Estado. El segundo tipo de tributo consiste en el concepto de capacidad contributiva, la cual no conlleva a la contraprestación y su retorno social se da en bienes y servicios colectivos.

TABLA 1.

Características de los tributos del sistema tributario colombiano

\begin{tabular}{|c|c|c|c|c|c|c|c|}
\hline \multirow{2}{*}{\multicolumn{2}{|c|}{$\begin{array}{l}\text { Sistema Tributario } \\
\text { Colombiano }\end{array}$}} & \multicolumn{2}{|c|}{ Obligatoriedad } & \multicolumn{2}{|c|}{ Contraprestación } & \multicolumn{2}{|c|}{ Destinación } \\
\hline & & Sí & No & Sí & No & General & Especifica \\
\hline \multirow{2}{*}{ Tributarios } & Impuestos & $\mathrm{X}$ & & & $\mathrm{X}$ & $\mathrm{X}$ & \\
\hline & Tasas & & $\mathrm{X}$ & $\mathrm{X}$ & & & $\mathrm{X}$ \\
\hline \multirow{3}{*}{$\begin{array}{l}\text { No } \\
\text { tributarios }\end{array}$} & Contribuciones & $\mathrm{X}$ & & $\mathrm{X}$ & & & $\mathrm{X}$ \\
\hline & Parafiscales & $\mathrm{X}$ & & & $\mathrm{X}$ & & $\mathrm{X}$ \\
\hline & Multas & $\mathrm{X}$ & & & $\mathrm{X}$ & $\mathrm{X}$ & \\
\hline
\end{tabular}

Fuente: Elaboración propia.

\section{Percepción social del Sistema Tributario por los pequeños contribuyentes}

La percepción social, para Melo (2017) es la concepción por parte del individuo referente a una situación de impacto social, de este modo, el conocimiento no versa de sensaciones sino de percepciones, ya que la forma en que el ser humano percibe se impone sobre el fondo de las razones y la objetividad. Henríquez, Rada y Torrenegra (2016) al igual que Fuenmayor y Villasmil (2008) definen la percepción como el proceso mediante el cual obtenemos datos de nuestro entorno a través de los sentidos, la representación del objeto, la información y su significado. Melgarejo (1994) muchas años antes, definió la percepción como las experiencias sensoriales que se interpretan y se adquieren por pautas culturales e ideológicas moldeadas y aprendidas desde la infancia.

Ahora bien y pasando a la relación entre sistema tributario y percepción social, estudios realizados por los profesores Castillo y Olivos (2014) concluyen que la "percepción de la calidad del gobierno tiene un efecto sobre la opinión acerca de la política tributaria, de tal forma que los sujetos verán con mejores ojos aumentos en los impuestos mientras mejor sea la calidad percibida" (p. 155). De allí que las actuaciones de quienes administran el Estado deben ser legítimas y bien percibidas, en tanto que, si por el contrario la percepción es negativa e ilegítima, a su vez también lo será el sistema tributario, a propósito, y "si el Estado pretende exigir el cumplimiento fiscal, deberá observar en sus propias actuaciones un comportamiento moral y ético, transparente y eficiente" (Vasconez, 2011, p. 152). Al respecto Lewis (2011) basado en estudios en psicologia fiscal ha asegurado que la evasión es el medio mediante el cual el contribuyente expresa su antipatia y desconfianza en el Estado. 
Asi que la confianza entre las partes intervenientes adquiridas en el vinculo legal y manifiesta en el sistema tributario colombiano, direccionan el pago honesto de los tributos, de este modo Cummings, Martinez, Vazquez, Mckee \& Torgler (2005) como se cita en Vasconez (2011), sustenatan que si la administración tributaria es percibida como honesta, justa e informativa y actúa al servicio de los contribuyente y no beneficiando a los gobernantes, los contribuyentes tendrán fuertes incentivos y motivaciones para los impuestos. En este mismo sentido, se manifiesta Torgler (2005) cuando advierte que la percepción que se tiene del retorno social del trubuto es un factor clave en el cumplimiento del pago del cago de este y de cumplir por parte de los ciudadanos el deber de contribuir con el Estado.

Chambilla, Santos, Carcausto y Marleni (2018) Dicen que en el contexto actual el cumplimiento de la obligación tributaria está ligada al grado de confianza que percibe el contribuyente frente a quien lo gobierna (Chambilla et al., 2018, p. 14). La confianza entre ciudadanos y el gobierno son indicadores de la existencia de una percepción generalizada del Estado como una "comunidad"; la confianza en el ejecutivo frente al cumplimiento y ejecución de las políticas públicas, hará que el contribuyente esté dispuesto hacer un sacrificio económico en la determinación del tributo, con la certeza que el gobierno será capaz de ejecutar los recursos en los fines fiscales y extrafiscales de los tributos.

Frente al sacrifico económico que realiza el contribuyente para contribuir con el financiamiento del Estado, Raymond (1987) puntualiza:

La percepción de una carga excesiva de gravamen sobre su renta distorsiona los cálculos presupuestarios y de eficiencia económica del propio individuo, lo que constituye una justificación plena de las actitudes evasoras" El contribuyente considera que un tributo excesivo afecta su calidad de vida y violenta el principio de justicia y equidad (p. 157).

La progresividad y regresividad del sistema tributario se evidencia en los impuestos directos e indirectos y es allí donde se distancia la percepción del contribuyente frente a la determinación del impuesto real. Prieto (1994) afirmó:

La percepción de la carga por el individuo debería coincidir con la carga real, pero normalmente no ocurre así. En la tributación directa si suele aproximarse los cálculos del individuo, ya que percibe el pago del impuesto como una reducción del poder de compra. En cambio, en la imposición indirecta la percepción del gravamen muchas veces es absorbido por el precio de mercado del bien o servicio adquirido, mostrándose menos reticente a aceptar este tipo de impuestos (p. 235).

De este modo, la percepción del sistema tributario como justo o injusto, se da respecto a la correspondencia percibida frente al retorno social y la transparencia en el manejo de los recursos públicos destinados al gasto social. Bruno (2013) responde: ¿por qué las personas pagan sus impuestos? Cita: "las actitudes de los contribuyentes están sin duda íntimamente relacionadas con las percepciones sobre el nivel de justicia distributiva codificado en un determinado sistema impositivo" (p. 44). 


\section{Conclusiones}

Se evidencia en lo descrito y los resultados de esta investigación documental, que, de acuerdo a los fines del Estado y su propósito de lograr la equidad social y el bien común, se hace necesario por parte de este tener un sistema tributario que garantice el cumplir su función y que es un deber del ciudadano contribuir a través del pago de los impuestos en contra prestación a lo percibido y beneficios que logra par parte del mismo Estado. No obstante, el recaudo del impuesto o tributo depende de la percepción del sistema tributario, el cual debe estar enmarcado por las condiciones constitucionales de este.

En el caso colombiano, ésta se encuentra fundada en principios tributarios que buscan establecer una estructura tal que permita un aumento de los ingresos fiscales sin afectar el bienestar socio-económico, tales como la equidad, progresividad y eficiencia; sin embargo, los cambios permanentes en las normas fiscales obedecen a necesidades coyunturales de gasto y reducción de déficit fiscal. De lo anterior se deriva la necesidad de realizar estudios o investigaciones de carácter empírico que le apunten a genera conocimiento sobre las consecuencias de estas reformas en la percepción de los contribuyentes y su impacto en los ingresos que tiene el Estado a partir de los impuestos.

Esta indagación permite observar que la percepción positiva que se construyen de los ciudadanos con respecto al sistema tributario es fundamental entender como los gobernantes invierten los ingresos fiscales como la principal fuente de financiamiento del Estado, constituidos por el aporte de todos los agentes económicos que lo conforman, ya que su, su aporte voluntario y sin ningún tipo de presión jurídica requiere como contraprestación la ejecución, manejo e inversión eficiente de dichos recursos en favor de toda la sociedad. Aquí nace un nuevo interés investigativo y es definir propuestas que indaguen por la manera en que el Estado invierte estos recursos y a qué tipo de población está dirigido.

Por último se advierte que la percepción y creencia negativa que tienen los ciudadanos frente al legislativo y ejecutivo de los recursos provocan comportamientos negativos frente al sistema tributario como: la evasión, la elusión remoción y traslación, entre otras prácticas que alteran la base impositiva y por tanto los niveles de ingreso, pues y como se ha dicho el recaudo eficiente y eficaz de los ingresos corrientes tributarios, dependen de la predisposición que tengan los contribuyentes frente al Estado, el gobierno y su obligación de dar.

\section{Reconocimientos y Agradecimientos}

El presente artículo es adelanto de resultado del proyecto titulado "Percepción social de los pequeños contribuyentes acerca de la constitucionalidad del sistema tributario colombiano". Nuestros agradecimientos a la Corporación Universitaria Uniremintong y la Universidad Católica Luis Amigo por el apoyo para el desarrollo del proyecto de investigación. 


\section{REFERENCIAS}

Alvaredo, F., y Londoño, J. (2014). Altos ingresos e impuesto de renta en Colombia, 1993-2010. Revista De Economía Institucional, 16(31). Recuperado de https:// revistas.uexternado.edu.co/index.php/ecoins/article/view/3904

Bravo, J. (2014). Los fines extrafiscales de los tributos. Foro Juridico, 13(2014), 236241. Disponible en http://revistas.pucp.edu.pe/index.php/forojuridico/article/ view/13790

Borda, L.V. (2007). Estado de derecho y Estado social de derecho. Revista de Derecho del Estado, 20(1), 73-96. Disponible en https://revistas.uexternado.edu.co/ index.php/derest/article/view/705

Bruno, V. (2013). ¿Por qué las personas pagan sus impuestos? Subjetividad y procesos cognitivos, 17(2), 37-47. Disponible en http://dspace.uces.edu.ar:8180/xmlui/ handle/123456789/2399

Casas, J. (2017). Implicaciones de los acuerdos del Fondo Monetario Internacional sobre la pobreza en Colombia. Económicas CUC, 38(1), 9-36. http://dx.doi. org/10.17981/econcuc.38.1.01

Castillo, J. C. y Olivos, F. (2014). Redistribución e impuestos: un análisis desde la opinión pública. Tributación en sociedad. Impuestos y redistribución en el Chile del siglo XXI. Santiago de Chile: Uqbar.

Chambilla, V., Santos, G., Carcausto, C. y Marleni, M. (2018). Sistema de percepciones y su relación con el cumplimiento de las obligaciones tributarias de los contribuyentes acogidos al nuevo RUS, en el distrito Alto de la Alianza, 2017. Chosica: Universidad Peruana Unión.

Chumaceiro, A. y Hernández, J. (2012) La legislación tributaria venezolana como promotora de la responsabilidad social empresarial. Revista OIKOS, 16(33). https://doi.org/10.29344/07184670.33.1041

Cummings, R., Martinez-Vazquez, J., Mckee, M. \& Torgler, B. (2004). Effects of Culture on Tax Compliance: A Cross Check of Experimental and Survey Evidence. [SCREMA Working Paper No. 2004-13l]. Crema: Gellertstrasse. https:// doi.org/10.2139/ssrn.661921

De la Torre, M. (2018). Utilización del sector financiero para el lavado de dinero: perspectiva desde la legislación ecuatoriana. Jurídicas CUC, 14(1), 145-166. https://doi.org/10.17981/juridcuc.14.1.2018.07

De Soto, M. y García, S. (2004). Ética y Hacienda Pública: el principio de justicia en la imposición. Crónica tributaria, (111), 9-26.

Espitia, J., Ferrari, C., Hernández, G., Hernández, I., González, J. I., Reyes, L. C., Villabona, J. y Zafra, G. (2017). Sobre la Reforma Tributaria estructural que se requiere en Colombia: reflexiones y propuestas. Revista de economía institucional, 19(36), 149-174. https://doi.org/10.18601/01245996.v19n36.06

Estrada, M. y Mármol, M. (2019). Política tributaria progresiva con equidad fiscal como mecanismo para impedir la evasión y elusión fiscal por el incumplimiento de las obligaciones tributarias por parte del sector del comercio informal. [Doctoral dissertation]. Universidad de El Salvador, San Salvador. 
Fuenmayor, G. y Villasmil, Y. (2008). La percepción, la atención y la memoria como procesos cognitivos utilizados para la comprensión textual. Revista de artes y humanidades UNICA, 9(22), 187-202. Recuperado de http://unicaedu.com/publicaciones/REVISTA_UNICA_ANO9_N22.pdf

González, J. I. y Corredor, F. (2016). La reforma tributaria en Colombia no es estructural, ni integral ni progresiva. Revista de Economía Institucional, 18(34), 173-200. https://doi.org/10.18601/01245996.v18n34.11

Henríquez, G., Rada, J. y Torrenegra, A. (2016). Measurement of Psychological, Economic and Social Variables to Identify Hidden Factors of Entrepreneurs in Barranquilla. Económicas CUC, 37(1), 179-202. https://doi.org/10.17981/econcuc.37.1.2016.08

Hernández, J., Chumaceiro, A. y Ravina, R. (2017). Estado populista y gestión de políticas sociales. Revista Negotium, 38(13), 49-61. Recuperado de http://www. revistanegotium.org/pdf/38/art4.pdf

Herrera, L., Larrea, C., Gallo, J. y Uribe, J. (2012). ¿Han sido eficientes y exitosas las reformas tributarias en Colombia en el período 1990-2009? Perfil de Coyuntura Económica, (20), 87-126. Disponible en http://hdl.handle.net/10495/6433

Jaimes, S. y Fuentes, V. (2017). Estudio de las reformas tributarias en Colombia y sus efectos sobre variables macroeconómicas. [Trabajo de Grado]. Universidad Católica de Colombia, Bogotá, D.C., Colombia. Disponible en http://hdl.handle. net/10983/15196

Jinú, C. G. (2013). Solidaridad de intereses: la transformación del derecho social como dominación en Lorenz von Stein. Revista de Estudios Sociales, (46), 7485. http://dx.doi.org/10.7440/res46.2013.09

Kohn, C. (2014). Teorías de la democracia y participación política. Episteme, 34(2), 7182. Disponible en http://190.169.30.98/ojs/index.php/rev_ens/article/view/9394

Lewis, A. (2011). The social psychology of taxatión. Journal of social psychology. 21(2), 151-158.

Linde, E. (2018). Fundamentos de Derecho administrativo: del Derecho del poder al Derecho de los ciudadanos. Madrid: Distribuciones Jurídicas.

López, A. H. y Chaparro, M.S. (2014). Equidad y ética en el recaudo tributario colombiano: 1990-2010. Apuntes del Cenes, 33(58), 83-108. https://doi. org/10.19053/22565779.3101

Masbernat, P. (2002). Garantías constitucionales del contribuyente: crítica al enfoque de la doctrina nacional. Ius et Praxis, 8(2), 299-357. http://dx.doi.org/10.4067/ S0718-00122002000200010

Masbernat, P. (2014). Justicia y sistema tributario. Una mirada desde la perspectiva inglesa. Dikaion, 23(1), 135-169. https://doi.org/10.5294/DIKA.2014.23.1.6

Melgarejo, L. (1994). Sobre el concepto de percepción. Alteridades, 4(8), 47-53. Recuperado de https://alteridades.izt.uam.mx/index.php/Alte/article/viewFile/588/586

Melo, D. (2017). Perception and Ontogenesis: transdisciplinary modulations of subjectivity. Fractal. Revista de Psicologia, 29(2), 103-109. https://doi. org/10.22409/1984-0292/v29i2/2159 
Mirrless, J., Adam, S., Besley, T., Blundell, R., Bond, S., Chote, R. y Poterba, J. (2013). Diseño de un sistema tributario óptimo: Informe Mirrless. Madrid: Editorial Universitaria Ramón Areces.

Montero, A. E. (1995). Hacia una estrategia española de competitividad. Madrid: Fundación Argentaria.

Musgrave, R. y Peggy, M. (1992). Hacienda pública teorica y aplicada. Madrid: McGraw-Hill,Inc.

Paredes-Chacín, J. (2017). Financial planning before the organizational perspective in cement companies of the Zulia State. Económicas CUC, 38(1), 105-132. https://doi.org/10.17981/econcuc.38.1.05

Paz, A., Harris, J. y Franco, F. (2016). Responsabilidad social gestión compartida con el emprendedor social en empresas mixtas del sector petrolero. Económicas CUC, 37(2), 47-68. https://doi.org/10.17981/econcuc.37.2.2016.03

Piza, J. y Sanchez, C. (2017). Reflexiones sobre la jurisprudencia y doctrina tributaria. Bogotá, D.C.: Universidad Externado de Colombia.

Prieto, J. (1994). Medidas para mejorar el cumplimiento de las obligaciones tributarias: Las amnistías fiscales. Anales de estudios económicos y empresariales, (9), 219-242.

Ramírez, I., Sánchez, D. A., y Silva, J. (2018). Complejidad del sistema tributario colombiano y su impacto en la informalidad empresarial. [Bachelor's thesis]. Bogotá, D.C.: Universidad Jorge Tadeo Lozano.

República de Colombia. Asamblea Nacional Constituyente. (1991). Constitución Política. Gaceta Constitucional, (127). Disponible en http://babel.banrepcultural. org/cdm/ref/collection/p17054coll26/id/3850

República de Colombia. Corte Constitucional. (15 de abril de 2010). Expediente D-7819. [Sentencia C-173]. M.P. Clara Inés Vargas.

Raymond, J. (1987). Tipos impositivos y evasión fiscal en España: un análisis empírico. Papeles de economía española, (30), 154-169.

Reales, A. (2016). La democracia representativa en el marco de los derechos humanos en Colombia. Jurídicas CUC, 12(1), 9-16. http://dx.doi.org/10.17981/juridcuc.12.1.2016.1

Restrepo, C. M. V. (2012). El principio de justicia en la tributación. Económicas CUC, 33(1), 205-224. Disponible en https://revistascientificas.cuc.edu.co/economicascuc/article/view/183

Retchkiman, B. (1976). Adam Smith, el Estado y las finanzas gubernamentales. Problemas del Desarrollo, Instituto de Investigaciones Económicas, Universidad Nacional Autónoma de México, 28(VII), 95-117. Disponible en https://www. jstor.org/stable/43906427

Rodríguez, J. (Ed.). (2015). La obligación tributaria y sus fundamentos constitucionales. Bogotá, D.C.: Universidad Externado de Colombia.

Roncallo, R. (2019). Facturación electrónica en Colombia: Una reflexión de sus efectos en el sector salud. Económicas CUC, 40(1), 27-46. https://doi.org/10.17981/ econcuc.40.1.2019.02 
Rozas, J. (2012). De la Justicia tributaria a la Justicia financiera. Revista Empresa y Humanismo, 15(2), 111-128. Recuperado de https://revistas.unav.edu/index. php/empresa-y-humanismo/article/download/2183/2044/

Sánchez, A. (2016). El género artículo científico: escritura y análisis desde la alfabetización académica y la retórica funcional. Medellín: Fundación Universitaria Católica del Norte. http://dx.doi.org/10.17533/udea.lyl.n73a09

Torgler, B. (2005). Tax Morale in Latin América. Public Choice, 122(1), 133-157. http://dx.doi.org/10.1007/s11127-005-5790-4

Toscano, Ó.M. (2013). La reforma tributaria de 1935 y el fortalecimiento de la tributación directa en Colombia. Apuntes del CENES, 32(56), 35-72. https://doi. org/10.19053/22565779.2442

Vasconez, B. (2011). Metodologías para medir la moral tributaria de los contribuyentes ty los resultados obtenidos. Ecuador: Centro Interamericano de Administraciones Tributarias. Recuperado de https:/www.ciat.org/Biblioteca/AsambleasGenerales/2011/Espanol/2011_tema_1.3_ecuador_Va\%CC\%81sconez.pdf

Vega, F., Brito, L., Apolo, N y Sotomayor, J. (2020). Influencia de la recaudación fiscal en el valor agregado bruto de los cantones de la provincia de El Oro (Ecuador), para el periodo 2007-2017. Revista Espacios, 41(15). Disponible en https:// www.revistaespacios.com/a20v41n15/20411515.html

Villabona, J.O. y Quimbay, C.J. (2017). Tasas efectivas del impuesto de renta para sectores de la economía colombiana entre el 2000 y el 2015. Innovar, 27(66), 91-108. https://doi.org/10.15446/innovar.v27n66.66805

\section{BIODATA}

José Wilmar Pino Montoya es Doctor en Filosofía de la Universidad Pontificia Bolivariana de Medellín (Colombia). Sus intereses de investigación han incluido la filosofía política, la educación, los temas de familia, la metodología de la investigación y la filosofía. Es investigador de la Facultad de Educación y Humanidades de la Universidad Católica Luis Amigó (Colombia). https://orcid.org/0000-0001-9035-2058

Juliana Carolina Farfán Rodríguez es Magister en Tributación y Política fiscal. Estudiante Doctorado en derecho económico y empresa. Miembro del grupo de investigación Capital Contable Uniremington (Colombia). https://orcid.org/0000-0002$5515-7035$

Ruby Stella Cabrera Jaramillo es Magister en Tributación y Política fiscal de la Universidad de Medellín (Colombia). Estudiante de doctorado en Materia Fiscal. Su línea investigativa se orienta a la investigación social en temas relacionados con la hacienda pública y los sistemas de tributación. Integrante del grupo de investigación CONTAS, investigador a de la Universidad Católica Luis Amigo (Colombia). https:// orcid.org/0000-0003-4505-382X 